\title{
THE RELATIONSHIP BETWEEN OWNERSHIP AND GROWTH
}

\author{
By Nguyen Minh $\mathrm{Ha}^{1}$
}

\section{Introduction}

The purpose of this paper is to investigate the relationship between ownership and employment growth. With a sample of 5,461 firms and using the Heckman two-stage model (to eliminate selection sample bias), the main findings are follows: Compared to firms with 100\% capital ownership, domestic firms with less than $50 \%$ state capital, domestic private firms, joint stock firms without state capital, $100 \%$ foreign capital firms, and joint venture (non-state and foreign) firms have positively significant impacts on employment growth. A change in ownership is not significant to employment growth.

The rest of this paper is organized as follows: Section 2 gives a literature review and some previous empirical evidence. Section 3 provides the econometric model for estimating firm growth. In Section 4, the data is described. Section 5 presents empirical results of the relationship between ownership and growth in Vietnam. The final section gives conclusions and policy implications.

\section{Literature Review}

Various ownership types may have various growth rates relying on flexibility and available resources. For firms affiliated with a company, the availability of resources is higher, leading to a higher probability of utilising opportunities. However, large firms might have a lower probability of identifying themselves due to the shortage of flexibility. Meanwhile, independent firms have greater flexibility, leading to a higher probability of identifying opportunities. Yet these firms have a lower probability of utilising their opportunities due to a shortage of resources (Delmar et al., 2002).

When investing in a host country, foreign firms face disadvantages which affect their growth and efficiency. With the theory of international operations, Hymer (1976) shows that, due to unfamiliarity with local environment, culture, politics, and economic situation, as well as the need for coordination across geographic distance, firms doing business abroad face the disadvantages of unavoidable costs. In particular, these are related to spatial distance, and include such costs as those of travel, transportation, and coordination over distance and across time zones; costs due to unfamiliarity with local culture and other sides of the local market; and costs due to a shortage of information networks or political influence in the host country. Furthermore, Dunning (1974) demonstrates that multinational firms also confront disadvantages, such as penalties exerted by the government, barriers to trade and goods, and disadvantageous exchange rates.

However, compared to domestic firms, foreign firms have several advantages that can translate into growth and efficiency. These advantages are known as the ownership-location-internalization framework presented by Dunning (1977) and summarized in the boundaries of multinational enterprises and the theory of international trade by Markusen (1995). The ownership advantage could be a product or a production process to which other firms do not have access (such as technology, patents, management skills, and intangible). The location advantage involves utilisation of the host country in order to earn profits and stimulate growth (cheap factor prices, access to customers, etc.). The internalization advantage is that the product or process is internally exploited (within the firm) at transferred prices rather than achieved at arm's length through markets. Moreover, foreign firms also take advantage of their ability to access the wider international trade 
network (Dunning, 1974 and 1993), which can be a great convenience for expansion.

Hence, due to their unique advantages and disadvantages, foreign firms are necessarily different from domestic firms both in the home country of the parent firms and in the host country. These disparities may lead to different growth dynamics (Blonigen and Tomlin, 1999).

Previous empirical evidence confirms different levels of growth between foreign and domestic firms. Almus and Nerlinger (1999) reveal that firms with tight links to external firms (subsidiary or affiliated firms) have, on average, significantly higher growth rates than firms which are entirely independent on medium-tech industries and non-innovative firms in other manufacturing sectors. In studying new firms in East Germany after the unification of the two Germanies, Brixy and Kohaut (1999) find that firms with West German majority ownership grow faster than new firms with East German ownership because they have more funds and have greater access to knowhow from the West. Chen and $\mathrm{Ku}$ (2000) study the effect of foreign direct investment (FDI) on firm growth in Taiwan and indicate that expansionary FDI (seeking to exploit the firm specific advantage: intangible assets in the host country) has a positive effect on sales growth, while defensive FDI (seeking cheap labour in the host country to decrease the cost of production) is neutral to sales growth. Blonigen and Tomlin (2001) analyze Japanese manufacturing plants in the US and find that Japaneseowned manufacturing plants there grow much faster than comparable US domesticowned plants. According to Davidsson et al. (2002), ownership form and legal form are two of the most important elements related to growth, and growth is different among ownership. Analyzing growth trends in the Indian computer industry for the period of 1991-2002, Mishra (2004) finds that, in hardware, private Indian and private foreign firms do better than public firms, since they have large networks for providing service and support to customers. Li et al. (2007) use data from Irish manufacturing from 19722003 to demonstrate that foreign plans grow more than those under Irish ownership.

However, in Gunning and Mengitae's (2001) study of Ethiopian manufacturing firms from 1989-93, state-owned enterprises have a positive effect on firm growth. Liu and Hsu (2004) study Taiwan's manufacturing firms and show that, for basic industrial firms engaged in FDI toward China, state-owned companies may have a negative effect on firm growth due to a substitution effect on the firm's domestic output. Conversely, traditional industrial firms investing into China may experience complementary effects on their output growth.

In the Vietnamese market, foreign firms also face the disadvantages and advantages mentioned above. However, due to a new developing country, foreign firms have faced the same problems in other countries they have experienced previously. Hence, they can reduce the disadvantages and increase the advantages so as to achieve growth and efficiency within Vietnam's market. Furthermore, the process of privatization, equitization and restructuring on state firms created different growth and efficiency among firms. Therefore, this paper will study the effect of each ownership on employment growth in Vietnam in recent years.

\section{Empirical Model of Growth}

\subsection{Econometric model}

The firm growth $(g)$ equation is given by the econometric model as follows

$$
g^{*}\left(t ; X_{i t}\right)=\beta^{\prime} X_{i t}+u_{i t}
$$

when $\beta^{\prime}$ is a vector of regression coefficients, $X_{i t}$ is a vector of independent variables, and $u_{i t}$ is a zero mean, constant variance disturbance term, $u_{i t} \sim$ Normal $\left(0, \sigma^{2}\right)$. 
If the model in the equation (1.1) is estimated by using the pooled ordinary least square(OLS) method, it produces biased and inconsistent estimators for the parameters in the model. Hence, we have to take into consideration this potential selection bias. The method of Heckman (1979) is proposed. The Heckman two-stage model undertaken for the growth equation is adjusted by the selection equation estimating probability of survival using a probit model, with steps as follows: First, the Probit selection model is estimated over the entire $N$ observations with the vector $Z$ by the maximum likelihood. Then, the inverse Mills ratio $\left(\lambda_{i t}\right)$ is constructed (i.e. the survival model generates a selection term based on the likelihood). Once $\lambda_{i t}$ has been obtained for each observation, the main equation (1.1) is estimated by OLS over the $n$ observations (the selected sample) reporting values for $g_{i}$ by including the estimated inverse Mills ratio $\left(\lambda_{i t}\right)$ as an additional variable to obtain an additional coefficient, $\mu$. More precisely, estimate:

$$
g\left(t ; X_{i t}\right)=\beta^{\prime} X_{i t}+\mu \lambda_{i t}+w_{i t}
$$

by OLS to obtain consistent estimates of $\mu$ and $\beta$ '. The $t$-test on the null hypothesis $\mu=0$ is a test of $\sigma_{u v}=0$. If a $t$-test indicates $\mu \neq 0$, then the sample selection bias is given. These second stage results relating to growth are selection - adjusted, since the procedure eliminates any bias in the estimates caused by a/the tendency for unobserved characteristics which affect firm survival to be correlated with unobserved characteristics which affect growth.

\subsection{Measurement of variables}

The first dependent variable is firm growth: Growth of firms can be measured in terms of employment (inputs). Firm growth is defined as

$$
\begin{gathered}
\text { Growth }(t)=[\operatorname{Size}(t)-\operatorname{Size}(t-1)] / \operatorname{Size}(t-1) \\
\text { where Size is employment size. }
\end{gathered}
$$

Another dependent variable is a status variable (Censorvar) to distinguish failure or survival. It is the dummy variable $(0,1), 1$ indicating the surviving firm (a selected firm) in the study period and 0 indicating the failure firm (a firm not selected) in the study period. This variable is used in the Probit model to estimate the effect of various factors on survival.

Explanatory variables are as follows: i) Independent variables: Firms in Vietnam are classified into eight types, with each type which represent to each ownership. They are that Public100pc: Dummy variable, it takes 1 if the firm has $100 \%$ state capital; 0 if otherwise. Domestic $<50 p c$ State: Dummy variable, it takes 1 if the domestic firm has more than 50\% state capital; 0 if otherwise. Domestic $>50 p$ state: Dummy variable, it takes 1 if the domestic firm has less than $50 \%$ state capital; 0 if otherwise. StateForeignJoint: Dummy variable, it takes 1 if the firm is a joint venture between state and foreign direct capital (FDI); 0 if otherwise. Domestic100pc: Dummy variable, it takes 1 if the firm is a domestic private firm; 0 if otherwise. JointStock: Dummy variable, it takes 1 if the firm is joint stock firm (without state capital); 0 if otherwise. Foreign 100pc: Dummy variable, it takes 1 if the firm is $100 \% \mathrm{FDI}$; 0 if otherwise. DomesticForeignJoint: Dummy variable, it takes 1 if the firm is a joint venture between non-state with FDI. OwnershipChange: Dummy variable, it takes 1 if the firm has a change in ownership in the study period; 0 if otherwise. ii) Other variables are initial debt and economic sector dummies (agricultural sector-AgriSector: firms in rural, agricultural, fishery, and forestry industries; industrial sectorInduSector: firms in mining, construction, and manufacturing industries; and service sector-ServSector) that are used as instrument variables for identification in the growth model in Equation 1.1.

\section{Data of Study}

Firms are drawn randomly from the total database, so the sample for this study is a random one. At year 2000, the number 
of randomly drawn firms is 6,000 firms and all firms are monitored to 2005 to generate a balanced panel data (i.e. 6,000 firms are drawn randomly at year 2000 and are observed in 2000, 2001, 2002, 2003, 2004, and 2005). Thus, each firm is observed for 6 years ( 6 observations), and covariates are observed responding to each observation. Each firm is monitored throughout the observation period by its own tax code. This dataset does not include new entrants, but it does include firms that exited during the study period. Hence, sample selection bias occurs with exit firms. After filtering unqualified firms according to these criteria, the total number of subjects is 5,461 firms. Hence, the data set for this research is a balanced panel data with both time-invariant covariates and time-variant covariates.

\section{Empirical Results}

Table 1 shows estimation results by the Heckman two-step method of the relationship between ownerships and growth in terms of employment. In estimation with the panel data, year dummies and some variables are used to control the differences in the model. In order to overcome multicollinearity as analysed in the above statistical descriptions, AgriSector and Public100pc are used as reference variables that represent the economic sector and the type of firm, respectively. In this research, the differences in the characteristics of economic sectors and initial debt are employed as the instruments for estimation.

In these regression results, there is statistical support for the selection adjustment, since the coefficient of the inverse Mills ratio (Lambda) is positive and statistically significant. There is a positive correlation between the error disturbances of the growth and the survival models, expressed by the positive sign of Rho $(\rho)$, and Lambda $(\lambda)$ summarises the estimated magnitude of the unmeasured effects on growth. This result shows that there is an upward bias in employment growth, meaning that there are measured features which tend to increase (decline) the exit rate while simultaneously increasing (reducing) firm growth. Hence, these results suggest that estimations of employment growth by the OLS are inconsistent, as there is an unmeasured selection effect in the sample. Wald test is staitical significant, suggesting that the model is fitted for the research.

State firms in Vietnam have greater advantages of exclusive utilisation of important industries in the economy, including gas, petroleum, electricity, coal, and minerals. Furthermore, they have more advantages of capital, as they are supported by financial sources from the government and get commitments (guarantees) from the government about their loans. Moreover, financial institutions are state firms, too. However, the efficiency and growth of state firms is not as great as expected and, at present, the government is re-structuring state firms. The different proportion of state capital in the firm will result in different growth.

i) For firms having a participation in state capital, regression results show that Domestic $<50 \mathrm{pcState}$ (domestic firms with more than $50 \%$ state capital), Domestic $>50 \mathrm{pcState}$ (domestic firms with less than $50 \%$ state capital), and StateForeignJoint (joint venture firms between state and foreign direct investment) have positive coefficients, compared to Public100pc (firms with 100\% state capital). The coefficients of Domestic $<50 \mathrm{pcState}$ and StateForeignJoint are not statistically significant, but the coefficient of Domestic $>50$ pcState is significant. This shows that, compared to the $100 \%$ state firms, firms with state capital of less than $50 \%$ (domestic capital is larger than 50\%) grow faster. Therefore, if the government wants state firms to grow, these firms should be privatized (completely or incompletely), to have less than $50 \%$ state capital, not more than $50 \%$ or not joint venture with FDI. 
Reasons for explaining firms with less than $50 \%$ state capital grow faster than $100 \%$ state firms are as follows:

- For firms with more than 50\% state capital, even if they are privatized and/or equitized, their state capital is dominant within the firm's total capital. Hence, the firm structure is not changed;

- Managers are still assigned by the government, and they run the firm identically to a state firm. Furthermore, the working habits and environment within the firm remain the same. Subsequently, these firms are not different from the $100 \%$ state capital firms, except in the proportion of capital.

- Meanwhile, firms with less than $50 \%$ state capital grow faster because the role of government in the firm is no longer dominant. However, the role of private ownership takes over; thus, these firms are no longer run according to old routines There are likely to be changes in the firm's structure, as well as new entrepreneurs and management who can improve the firm's efficiency and growth.

This result is consistent with Liu and Hsu's (2004) study of Taiwan's manufacturing firms. That is, state-owned firms may have a negative effect on firm growth due to a substitution effect on the firm's domestic output. However, this results is opposite with Gunning and Mengitae's (2001) study of Ethiopian manufacturing firms as Gunning and Mengitae showed that state-owned firms have positive effect on firm growth.

ii) In terms of domestic private ownership, the coefficients ofDomestic100pc and JointStock are positive and statistically significant, meaning that, compared to the firm with $100 \%$ state ownership, domestic private and joint stock firms display a faster growth rate. This result is in line with Mishra's (2004) findings of computer industry in India. This result may be explained by reasons as follows:
- Domestic private firms in Vietnam are younger and smaller than state firms. Young and small firms can grow faster than older and larger ones (Ha, 2010).

- In addition, in Vietnam, domestic private firms are more flexible and dynamic, while state firms are cumbersome and bureaucratic because they are influenced by an old mechanism (the centrally-planned mechanism). Thus, domestic private firms are more likely to increase in size.

- Furthermore, entrepreneurs in domestic private firms are from the young generation, whereas managers of state firms tend to be from the older generation, which lived and was educated in the long period of war and the centrally-planned economy. As a result, these firms have an inferior level of entrepreneurial acumen and managerial ability, and they do not run efficiently.

- Another aspect is that, due to their firms' capital belonging to the state, managers of state firms do not bear any pressure of increasing efficiency or growth, so they have no incentive to expand in size.

iii) With respect to foreign ownership, the coefficients of Foreign100pc and DomesticForeignJoint appear as positive and statistically significant. These results suggest that, compared to $100 \%$ state capital firms, foreign firms grow faster. This is likely to explain that although foreign firms confront disadvantages such as unfamiliarity with the environment, culture, politics, and economics of their host country, as well as increased costs of travel, transportation, and coordination over distances and across time zones (Hymer, 1976), they nevertheless have several advantages over domestic firms. These advantages include ownership advantages (technology, patents, management skills, and intangible assets), location advantages (cheap prices of factors and access to customers), internalization advantages (the product or process is exploited internally 
within the firm at transferring prices that benefit foreign firms), and the advantage of access to a wider international trade network (Dunning, 1977 and Markusen, 1995). These advantages promote the growth of foreign firms.
This result is according to findings of Blonigen and Tomlin (2001) in United State, Chen and $\mathrm{Ku}(2000)$ in Taiwan, Li et al. (2007) in Irish, Liu and Hsu (2004) in Taiwan, and Mishra (2004) in India.

Table 1

The Heckman two-stage model for firm growth

\begin{tabular}{|c|c|c|}
\hline \multirow{2}{*}{ Explanatory Variables $(*)$} & \multicolumn{2}{|c|}{ Employment growth } \\
\hline & Coefficients & Std.Errors \\
\hline Constant & -0.0024 & 0.1913 \\
\hline Domestic $<50$ pcState & 0.0948 & 0.0768 \\
\hline Domestic $>50 \mathrm{pcState}$ & $0.1573 * * *$ & 0.0256 \\
\hline StateForeignJoint & 0.0986 & 0.0649 \\
\hline Domestic100pc & $0.0742 * * *$ & 0.0237 \\
\hline JointStock & $0.1409 * *$ & 0.0637 \\
\hline Foreign100pc & $0.1787 * * *$ & 0.0583 \\
\hline DomesticForeignJoint & $0.1624 *$ & 0.0848 \\
\hline Ownership Change & -0.0506 & 0.0340 \\
\hline \multicolumn{3}{|c|}{ Probit Function $(* *)$} \\
\hline Constant & -0.1363 & 0.1127 \\
\hline \multicolumn{3}{|c|}{ Vairables of the identifying restrictions: } \\
\hline Initial debt & $0.1191 * * *$ & 0.0312 \\
\hline Industrial Sector & $0.4681 * * *$ & 0.0940 \\
\hline Service Sector & $0.4800 * * *$ & 0.0938 \\
\hline Rho & \multicolumn{2}{|c|}{0.589} \\
\hline Lambda & $0.4716^{* * *}$ & 0.1710 \\
\hline No. Obs & \multicolumn{2}{|c|}{21,102} \\
\hline Censored Obs (Uncensored Obs) & \multicolumn{2}{|c|}{$7,617(13,485)$} \\
\hline Wald test & \multicolumn{2}{|c|}{$\chi^{2}=671.9$ Pro $>\chi^{2}=0.0000$} \\
\hline
\end{tabular}

Note: (*) Control Variables for Growth function: Lnage, LnageSq, Lnsize, Capintensity, Salelabor, EBTlabor, ROS (returns on sales), ROA (returns on assets), LagLeverage, Investment, Year dummy. (**) Control Variables for Survival function: Lnsize, Lnassets, Capintensity, DomesticFirms, ForeignFirms, Salelabor, EBTlabor, ROS (returns on sales), ROA (returns on assets), Leverage, Year dummy.

The reference groups for dummies are Public100pc and AgriSector. $* * *$ is significant at $1 \%, * *$ is significant at $5 \%$, and $*$ is significant at $10 \%$.

\section{Conclusion}

\subsection{Conclusion}

In this paper, the Heckman two-stage model is employed to eliminate the sample selection bias in the sample in order to estimate firm growth. Principal findings are as follows:

It is important to conduct the twostage procedure to correct selection bias in estimating growth because there is a presence of significant selection effects in the sample that the estimation of growth by the OLS approach may be inconsistent. The coefficient of the inverse Millsratio(Lambda) is negative and statistically significant in the employment growth model.
Compared to firms with $100 \%$ capital ownership, domestic firms with less than $50 \%$ state capital and domestic private firms grow faster in the employment. In addition, joint stock firms without state capital, $100 \%$ foreign capital firms, and joint venture (nonstate and foreign) firms have positively significant impacts on employment growth. A change in ownership is not significant to employment growth.

\subsection{Policy implications}

This paper may have some value for practitioners for both managers and the government because micro- and macrolevel policies will increase/decrease firm growth. From the above empirical results 
of the relationship between ownership and growth, some policy implications are drawn that can be introduced into Vietnam's situation as follows:

Compared to firms with $100 \%$ state capital ownership, domestic private ownership grows faster in terms of employment, so assistant programmes and policies of stimulating domestic private ownership to start-up and grow should be issued.

The process of privatizing state firms helps these firms to grow. However, if the government wants state firms to grow, these state firms should be privatized completely or incompletely-with state capital being less than $50 \%$ of the total capital. Moreover, a decrease and/or deletion of direct and indirect support from the government should be instituted for state firms (compared to in previous periods) to generate equal business environment across ownerships.

Assistant programmes and policies of encouraging other ownerships (joint venture, joint stock, and foreign direct investment) are also issued, since they experience higher growth rates in employment compared to firms with $100 \%$ state capital.

\section{References}

Almus, M. and Nerlinger, E. A. (1999), 'Growth of New Technology - Based Firms: Which Factors Matter?', Small Business Economics, 13, pp.141-154.

Blonigen, B. A. and Tomlin, K. (2001), 'Size and Growth of Japanese Plants in the United States', International Journal of Industrial Organization, 19, pp.931-952.

Brixy, U. and Kohaut, S. (1999), 'Employment Growth Determinants in New Firms in Eastern Germany', Small Business Economics, 13, pp.155-170.

Chen, T. J. and Ku, Y. H. (2000), 'The Effect of Foreign Direct Investment on Firm Growth: The Case of Taiwan's Manufacturers', Japan and the World Economy, 12, pp.153-172.

Davidsson, P. Kirchhoff, B., Hatemi-J, A. and Gustavsson, H. (2002), 'Empirical Analysis of Business Growth Factors Using Swedish Data', Journal of Small Business Management, 40(4), pp. 332-349.

Delmar, F., Davidsson, P. and Gartner, W. B. (2003), 'Arriving at the High - Growth Firm', Journal of business Venturing, 18 , pp. $189-216$.

Dunning, J. H. (1974), 'The Distinctive Nature of the MultinationalEnterprise', in Dunning, J. H., Economic Analysis and the Multinational Enterprise, George Allen \& Unwin Ltd, 1974.

(1977), 'Trade, Location of Economic Activity and MNE: A Search for an Eclectic Approach', in Olhlin, B., Hesselborn, P. O. and Wijkman, P. M. 'The International Allocation of Economic Activity. London: Macmillan, 1997.

(1993), 'Multinational Enterprises and the Global Economy', Addison - Wesley Publishing Company Inc., 1993.

Gunning, J. W. and Mengistae, T. (2001), 'Determinants of African Manufacturing Investment: The Microeconomic Evidence', Journal of African Economies, Vol. 10, AERC Supplement, 2, pp. 48-80.

Heckman, J. J. (1979), 'Sample Selection Bias as a Specification Error', Econometrica, Vol. 47, No. 1, pp. 153-161.

Hymer, S. and Pashigian, P. (1962), 'Firm Size and Rate of Growth', 'The Journal of Political Economy, Vol. 70, No. 6, pp 556-569

Hymer, S. H. (1976), 'The International Operations of National Firms: A Study of Direct Foreign Investment', 
The Massachusetts Institute of Markusen, J. R. (1995), 'The Boundaries of Technology, 1976. Multinational Enterprises and the Theory of International Trade', Journal of Li, Q., Walsh, P. P. and Whelan, C. (2007), 'Jobless Growth through Creative Destruction: Ireland's Industrial Development Path 1972-2003', in Unpublished paper in Seminar on 'The Survival and Growth of Firms' at the Centrer for Economic Performance, LSE, London, 2007.

Liu, W. C. and Hsu, C. M. (2004), 'Financial Structure, Corporate Finance, and Growth of Taiwan's Manufacturing Firms', It is downloadable from http:// faculty.washington.edu/karyiu/confer/ Economic Perspectives, Vol 9, No. 2, pp. 169-189.

Mishra, V. (2004), 'Size, Age \& Firm Growth: The Computer Industry in India', It is downloadable from http://ssrn.com/ abstract=520822 or http://unpan1.un.org/ intradoc/groups/public/documents/ APCITY/UNPAN023828.pdf

Ha, Nguyen Minh (2010) "Impact of Age and Size on Firm Growth in Vietnam". Science Journal of HCMC Open University. Vol 2 (17), pp.137-146. tok04/papers/liu\&hsu.pdf 